\title{
Reviews/Comptes rendus
}

\section{The Study of Second Language Acquisition}

\author{
Rod Ellis \\ Oxford University Press, 1994, ISBN 0-19-437189-1
}

The aim of this book, in the author's words, is to "develop a framework for describing the field [of second language acquisition] as it currently exists and to use this framework to provide an extensive account of what is currently known about L2 learning and L2 learners." The result is an extremely thorough, well-designed, and up-to-date overview of the field, outlining the principal issues that have been addressed, the theories that have emerged, their main findings, and lines of further research.

This aim is amply justified by the fact that the scope of second language acquisition (SLA) research has broadened considerably in the last few decades. Along with the existing focus on the grammatical properties of language learning, concern is growing for the sociolinguistic aspects of language acquisition, and increasing attention is being paid to research in linguistic theory. Thus research in SLA is no longer limited to post hoc descriptive interpretations of second language learning facts, but is developing into the kind of research that seeks to test predictive hypotheses, often related to issues in theoretical linguistics. Ellis' book successfully captures the different aspects of the development of SLA research and its present-day state and presents them in a clear, well-organized, and readable manner.

The format of the book has a significant impact on the effectiveness of the work. It is structured around four main areas that make up the proposed general framework for investigating SLA. These areas have different focuses: a focus on learning, describing the learner language (area 1) and explaining learner-external factors (area 2) and learner-internal mechanisms (area 3) affecting the L2, and a focus on the learner (area 4). The book consists of 15 chapters grouped into seven parts that include an introductory section, a section on each main area, another section specifically dealing with SLA in the classroom, and a conclusion.

Part One provides an overview of the topic, outlining the main areas of research in SLA by presenting a concise summary of each area and directing the reader to the chapter in the book that deals with each issue. This introductory part renders the book accessible to the reader as it paints a general picture of the topic and lays out the organizing framework of the rest of the book. The selective reader is thus able to refer to the chapters that deal with his or her particular interest in more detail. Therefore, the book, which may 
appear difficult to handle due to its considerable length (over 800 pages), becomes easily accessible as a reference book for students and researchers.

Part Two introduces the focus on learning, starting the exploration of SLA with the study of the characteristics of learner language. Its four chapters thoroughly cover different aspects of learner language such as learner errors and error analysis, acquisition orders and developmental sequences, variability in L2, and the pragmatic aspects of learner language. As in subsequent sections, Ellis describes and explains the topic in light of the most important theories that have characterized research from a diachronic perspective and of an up-to-date review of the current trends. He offers a valuable critical account of the theories, pointing out their strengths and weaknesses and clarifying where they stand in current research, while keeping an explicitly partial viewpoint.

In Part Three, the author offers an extensive analysis of the effect of external influences such as social factors that include the role of the setting for acquisition (natural vs. educational) and of such sociolinguistic variables as age, sex, social class, and ethnic background. He goes on to review the effect of input and interaction in the shaping of the learner language. The issues depicted in this section thus will no doubt be of use to both the researcher and the language teacher interested in finding out about the sociolinguistics of $\mathrm{L} 2$ learning and the relevant role that input and interaction play in L2 acquisition. The following section, Part Four, looks at the effect of internal factors by examining various theories of the mental processes involved in SLA, including the degree of interference of the first language manifest in language transfer, cognitive accounts of L2 learning as exemplified by the interlanguage theory, and the role of linguistic universals, such as those found in first language acquisition, in shaping the L2.

In Part Five the focus switches to the language learner, exploring individual differences such as motivation and the various learning strategies that represent the learner's deliberate attempts to learn. Part Six is of particular interest for the ESL teacher because it turns to the study of SLA in the classroom setting and examines classroom-based and classroom-oriented research from the perspective of interaction and formal instruction. It analyzes the forms and effects of interaction and participation and reflects on the benefits and constraints of instruction, including examples of studies dealing with these issues. Indeed, throughout the book, the description of the different topics in SLA research is illustrated by examples of crucial experimental studies that supply the necessary empirical evidence to support the theories and provide direct examples of the line of research that is and has been carried out.

Part Seven concludes the book with a discussion of the kind of data required to investigate $\mathrm{L} 2$ acquisition, the implications of theory-building in SLA research, and the applications of its results to other fields such as 
language pedagogy. Every chapter closes with a list of further readings on the topic reviewed to facilitate further study. In addition, the extensive bibliography at the end of the work constitutes a substantial and worthy bibliographic reference for the researcher in SLA.

A couple of shortcomings may be pointed out. On the one hand, most of the examples of studies dealing with the learner language concentrate on the acquisition of grammatical structures, that is, syntactic and morphological structures. Not much is found on second language acquisition of phonology. However, this reflects the fact that much more investigation has been devoted to the study of L2 syntax and morphology than to phonology acquisition. The researcher interested in L2 phonology will appreciate this book as an essential general overview of the field of SLA, but without a particular focus on phonology. On the other hand, the book lacks a section on the types of methodology used in SLA research, or describing the basics of statistics, which could be helpful considering the relevance of statistics in drawing conclusions in disciplines such as SLA. Nevertheless, the book does provide some information on methodology in cases when it is particularly relevant. Moreover, the reader requiring information on statistics can obtain it from a more specific work on statistics, because statistics is a tool to SLA rather than a subarea of this field and, as such, lies beyond the scope of this already lengthy book.

The author claims that the book is addressed to students beginning their study of L2 acquisition looking for an overview of the topic and their current state, and to the SLA researcher who is an expert in one of the areas of SLA research but for whom this book can be useful as a reference book. As indicated above, the book is definitely suitable for the student and the researcher in need of an extensive survey of the field, and it can be helpful as a reference book. It is probably more useful as a reference book than as a class textbook due to its considerable length and ample coverage. Nevertheless, it is also recommendable as a textbook in a graduate course intended to introduce students into research in SLA because, together with the necessary background on the topic, it provides ideas for further research. A reader with some background, or a particular area of interest, can use the book in a more selective way, directly choosing those parts or chapters of interest.

In addition to these types of audience, Ellis emphasizes that the principal kind of reader is the second/foreign language teacher, arguing that "unless we know for certain that the teacher's scheme of things really does match the learner's way of going about things, we cannot be sure that the teaching content will contribute directly to language learning." Language teachers can indeed benefit from this thorough description and explanation of how second language learning takes place, knowledge that is of obvious relevance to the practice of language teaching. The teacher or student who is only interested in a brief overview of the topic, however, should be aware 
that this is not a short handbook on the topic, but a rather extensive and in-depth coverage of the field. Unfamiliarity with notions of linguistic theory and SLA should not deter any reader. The book is written in a clear explanatory way and provides an introduction to those theories that are relevant to a particular topic in SLA research. For instance, the Theory of Universal Grammar is summarized and explained in the pertinent chapter. Furthermore, a glossary of terminology related to the field appears at the end of the book to facilitate the accessibility of the reading. It can also be used for quick consultation by students of SLA.

In summary, this book is a comprehensive, accessible, and up-to-date survey and critical overview of the current state of the art of SLA research. The Study of Second Language Acquisition is a valuable and essential contribution to the field, highly recommendable for the second language researcher and the second language teacher interested in knowing the processes underlying the acquisition of an L2. The wide coverage of the book makes it unlikely that a reader interested in the topic will not reap benefit from the reading.

Julio Cebrian

\section{The Reviewer}

Julio Cebrian is a graduate student in the Linguistics Department at the University of Toronto. He has taught English as a foreign language in Barcelona, Spain, and Spanish at the College of the Holy Cross, in Massachusetts. His main interest is in second language phonology acquisition.

\section{Language and Culture in Multilingual Societies: Viewpoints and Visions}

\section{Makhan L. Tickoo (Ed.)}

Anthology Series 36. SEAMEO Regional Language Centre, Singapore, 279 pp. RELC P429-95. ISBN 9971-74-053-2. ISSN 0129-8895, 1995

If the purpose of an anthology is to bring together different perspectives on a theme, then this is a successful anthology. Through the backgrounds of the authors as well as the languages and cultures they examine, the 17 invited papers include perspectives from the ASEAN region (Singapore, Malaysia, Indonesia, the Philippines), other Asian countries (Japan, Korea, India), and several Western countries (Australia, Canada, USA, UK).

More interesting perhaps than the diversity of the authors and their topics is the diversity of viewpoints and visions. The papers in the first section look at theories and issues in Language and Culture in Cross-cultural Contexts, outlining some practical implications for teaching and teacher education.

Braj B. Kachru opens with the case for English as a medium of plural canons. "The medium per se ... has no constraints on what message-cultural or social-we transmit through it" (p. 1). 
The strands of multiculturalism in world Englishes ... manifest the multilinguals' creativity [through] the cultural identity of a varietyNigerian, Indian, Singaporean-which is distinct from the Judeo-Christian identity of the language ... [and through] discourse strategies and speech acts [that] are transcreated into English to approximate the Asian and African backgrounds, religious subgroups, and interactional contexts of a variety of African and Asian languages: They include culturespecific patterns of apologies, compliments, condolences, persuasion, politeness, and requests. (p. 4)

Some of these culture-specific patterns are illustrated in detail in Part Three of the anthology. Kachru argues for World English Literatures and a Transcultural Canon that is not marginalized. He revisits many related issues and reminds us that only 50 years ago the marginalizing attitude now exhibited against certain world Englishes was exhibited in Britain against American English (p. 14).

The next two papers in this first section focus on developing intercultural competence. Michael Byram describes in detail a course given at Thames Valley University to train language learners as ethnographers so that learners can prepare themselves to communicate in the new multilingual and multicultural Europe. Although an increasing number of students spend a year studying in foreign European countries, their language skills do not necessarily improve and they may remain observers to the culture (p. 28). This is a phenomenon that has ESL parallels. One goal of the ethnography course is to promote tertiary socialization: reorganization of schemata; relativization of values and actions (p. 22). The desired

intercultural speaker is someone who can operate their linguistic competence and their sociolinguistic awareness of the relationship between language and the context in which it is used, in order to manage interaction across cultural boundaries, to anticipate misunderstandings caused by differences in values, meanings and beliefs, and thirdly, to cope with the affective as well as the cognitive demands of engagement with otherness. (p. 25)

Intercultural competence is defined in terms of four kinds of knowledge and skill, four savoirs, each of which is defined and exemplified in detail (pp. 25-27).

1. Attitudes/values/savoir être (e.g., ability to take the role of cultural intermediary between one's own culture and the foreign culture, including in situations of conflict).

2. Ability to learn/savoir apprendre (e.g., ability to identify situations of initiation into specific dimensions of a society and the rites of passage involved). 
3. Knowledge/knowing that/savoirs (e.g., being aware of the [conflictual] relationship between differing national perspectives on historical events).

4. Skills/knowing how/savoir faire (e.g., an ability to take account of perceptions of the learner's own culture and cultural identity imported into intercultural relationships by speakers of the target language).

For Alvino Fantini intercultural competence is characterized by the ability to establish and maintain positive relationships; the ability to communicate effectively, with minimal loss and distortion; and the attainment of an appropriate level of compliance and cooperation with others (p. 38). To be interculturally effective requires competence in the target language and the target culture and in some cases competence to deal with other nonnative speakers using a common target language (p. 39). Thus cultures as well as communicative and interactive styles have to be compared and contrasted so that students become aware of their own cultural lenses, that of the target language, and that of other interlocutors (p. 39). Building on a Whorfian linguistic relativity, he develops a notion of cultural literacy and suggests practical ways to develop this in learners and teachers of foreign languages.

Following from the reality of nonnative speaking interlocutors, Andrew Gonzalez looks at the cultural content in English as an International Auxiliary Language (EIAL) as in the language of scientific discourse, international trade, and international diplomacy. In fact, in these areas English is the dominant language, rather than an auxiliary language (p. 58). The cultural content of these uses of English translates itself into the culture of science and technology, the culture of international business and economics, and the culture of geopolitics (p. 60).

The last two papers in this first section drawing on contrasting teaching situations both argue that teachers must be aware of the rules of discourse of the students' native language as well as the target language, so that explicit comparisons can be made. Andy Kirkpatrick gives examples of the sentence structure, discourse rules, and text grammar of Modern Standard Chinese to show how this could work for English speaking learners of MSC. He also argues that the techniques used to impart communicative ability are often educationally and culturally inappropriate by comparing teacher-student roles and notions of a "good teacher" under a communicative approach versus a Chinese approach. He reiterates the theme of the anthology: "teacher training courses need to respect and take into account the educational traditions and communicative practices of different countries and cultures" (p. 77).

Harry Krasnik examines the role of expatriate teachers in Southeast Asia and argues that their "value which derives essentially from being a native speaker on English" will decrease as the need for intercultural communication is increasingly recognized. He predicts that Western norms and values 
will form the cultural groundwork for communication norms in the ASEAN countries, but that this will be modified to preserve "aspects of the local cultures that are felt, or even deemed, to be inviolable, or even superior to their Western variants" (p. 83). He draws on experiences from pre-departure programs in Indonesia and includes some suggestions for helping students make the transition to Western practices, such as asking questions or being self-motivated.

The four papers in the second section, Cultural Issues in Language Education, reveal the cultural biases of textbooks in Asia, Canada, the two Koreas, and Singapore in different ways. Makhan L. Tickoo begins by highlighting the failures of the currently dominant paradigms of ELT both in the "authentic" texts or products they sanctify and the "authentic" English-only processes they endorse. He argues for an approach informed by a fuller view of Asian realities and the goals of ELT in Asian classrooms.

Jane Nicholls analyzes "official" Canadian English language textbooks and argues that they "represent an overwhelmingly monocultural sociopolitical reality of an English-speaking majority" (p. 112).

Although the characters are ... likely to be members of a minority ...

[they] almost always embrace the values, manners and mores, religion and socio-economic status of members of Canada's Anglo majority....

Absent in these textbooks is the variety and depth of Canadian voices and experience. (p. 113)

She then suggests strategies using oppositional and solidarity narratives to promote a unified and yet culturally diverse Canadian society.

Martin Jonghak Baik and Rosa Jinyoung Shim show us that "the conflicting political and social systems in the two Koreas have resulted in the representation of societal values and in the portrayal of English-speaking cultures that are vastly different in the English textbooks of North and South Korea" (p. 126). In the North Korean texts, English-speaking cultures are viewed as objects of contempt; whereas in the South Korean texts, the relationships between men and women are portrayed to be exactly the same as those in South Korea, and the West is viewed as an object of envy and respect.

Vanithamani Saravanan relates Tamil language texts to the official Singapore policy "to promote the use of mother tongues to ensure identification with and maintenance of traditional cultures and their values" and the ultimate goal of cultural pluralism. She argues that these objectives are not fully achieved, largely because the use of Tamil in the text does not reflect the use of Tamil in multilingual Singapore. She provides suggested improvements and argues for a model for metacultural awareness.

The final section of the anthology includes descriptions of the role of Culture in Linguistic Discourse. The seven papers provide the specific ex- 
amples of how language and culture interact in multilingual societies that are so necessary to flesh out the theoretical and educational issues involved. Space dictates that I do little more than relate the titles and authors: The Javanese conversational narrative in pattern and practice (Laine Berman); Cultural meaning in World Englishes: Speech acts and rhetorical style (Yamuna Kachru); Power of English loanwords in Japanese discourse (Reiko Hayashi and Takuo Hayashi); Understanding self and face through compliment responses (LuMing R. Mao); Agreeing and disagreeing in Indian English discourse: Implications for language teaching (Tamara M. Valentine); Understanding the internal filter in cross-cultural reading (Azlina Murad Sani); and Creative literature, culture and comprehension (Larry Smith and Sandra Tawake). Each of these papers provides valuable insights that remind us how differently language works in different cultures.

The papers in this anthology vary not only in their viewpoints and visions, but also in their level of sophistication and presentation. Some result from master's work - and might provide inspiration for future master's students; others are written by senior academics with many years and pages of experience to draw on. Some make many references to diverse disciplines and theories; others are more specifically located in a particular vision. Some are polished; others are in need of some revision (e.g., the references for the second paper in Section Two).

Although the introduction gives us an excellent summary of the book, it is in the nature of an anthology that the reader must select critically. Neither the theoretician looking for a coherent theory of language and culture in multilingual societies, nor the graduate student looking for a comprehensive overview of the field, nor the classroom teacher wondering how to cope with the different cultural norms in her or his multicultural class will find ready answers. What they will find are issues, arguments, and teaching suggestions that they can contest, adopt, or adapt for themselves.

Readers of this anthology should be convinced that English can and does exist as a vibrant language distinct from native-speaking cultures or that intercultural communicative competence should be an essential part of what we teach in ESL/EFL classrooms where English is to be used to express different cultural realities. The implications for language teachers are that we should review the cultural content of what we teach (whose variety, which functions) and how we teach it (the materials and the methods); in addition, we should include activities that promote intercultural understanding among our learners (e.g., training learners as ethnographers; engaging in contrastive discourse activities; or following the presentation and practice of new language, including sociolinguistic exploration, cultural exploration, and intercultural exploration [p. 42]). We expect learners to undergo transformation when they learn English. The challenge from this anthology is to 
transform our teaching to respond to the multilingual, multicultural society in which we live.

Sheena Gardner

\section{The Reviewer}

Currently in ESL/EFL teacher education at the University of Winnipeg, Sheena Gardner leaves Canada this year to join the Centre for English Language Teacher Education, University of Warwick. Her research interests include Sudanese onomastics, educational transformation in the Czech Republic, and factors affecting learning among adult immigrants.

\section{Testing in Language Programs}

\section{James Dean Brown}

Englewood Cliffs, NJ: Prentice Hall Regents, 1996 ISBN: 0-13-124157-5

(paperback)

Although few ESL teachers see themselves as language testers, most are responsible for placing students in appropriate ability levels, diagnosing individual strengths and weaknesses, and assessing students' progress and achievement in ESL classes. In addition, many ESL teachers and administrators find themselves in the position of preparing students for large-scale standardized tests (e.g., TOEFL) or making recommendations and decisions based on students' scores on such tests. In each of these situations the ESL teacher needs to be able to interpret test scores, make accurate assumptions about test content, understand basic principles of test construction, and help students perform their best. James Dean Brown's recent book Testing in Language Programs provides ESL teachers and administrators with the information they need to make sound decisions about testing at both the classroom and program level.

As a text for a course in ESL testing, Brown's book is aimed at practicing teachers, administrators, and ESL teachers in training. Each chapter is approached from the perspective of norm-referenced versus criterion-referenced testing. In general, norm-referenced tests are those designed to measure global proficiency; each student's performance is assessed relative to other students' scores or to established norms. Norm-referenced tests are typically used to make program-level decisions such as whether to admit a student to a particular institution (e.g., a college or university) or where to place a student in a language program. In contrast, criterion-referenced tests are those used in a classroom situation to measure students' achievement in a language course or to diagnose the need for further instruction. A student's score on a criterion-referenced test is interpreted without reference to other students' scores.

The issues that surround norm-referenced testing will necessarily be of more interest to program administrators, whereas classroom teachers will 
find criterion-referenced testing more useful. However, because decisions based on the results of both norm-referenced and criterion-referenced tests can profoundly affect ESL students' lives, Brown encourages teachers and administrators alike to learn about both types of testing. Thus, whether the reader of Testing in Language Programs is a teacher or an administrator, the author's goal is for both to "learn how to do all types of testing well."

The book is divided into nine chapters. Chapter 1 introduces basic testing terminology. Different types of tests are compared, the purpose of testing is discussed, and the author presents useful guidelines to help teachers determine the type of tests that will best meet the needs and purposes of their courses and programs.

Chapter 2 deals with issues that teachers need to address before they adopt, develop, or adapt a particular language test. Brown stresses the importance of examining our views about language teaching and learning prior to determining what constitutes a useful test. This point cannot be overemphasized. All too often a test is used simply because it is available. The result is that strict tests of grammar are frequently used to assess achievement in a program that focuses on overall communicative competence, or a written test is used to place students in a conversation class. Importantly, teachers and administrators need to be confident that the tests they use reflect their program goals and their position with regard to what constitutes good language teaching and learning. To help us understand the relationship between teaching and testing practices, Brown presents a brief but informative history of the language testing movement.

Chapter 3, Developing and improving test items, provides practical information about test development. The reader is introduced to various types of test items, general guidelines are presented to help teachers develop or critique tests, and numerous examples are used to illustrate common pitfalls in testing. Included in this chapter are approaches for scoring open-ended questions (e.g., essays). Specific features that make this chapter valuable include scales for scoring compositions and checklists for evaluating different types of test items.

Ways of describing and reporting test results are presented in Chapter 4; Chapter 5 deals with the interpretation of test scores. In both of these chapters, basic descriptive statistical techniques are introduced. Concepts covered include measurement scales, graphic representations of frequency distributions, measures of central tendency and variability, types of distributions, and standard scores. Correlation is covered in Chapter 6 in order to prepare the reader for issues of reliability and validity presented in Chapters 7 and 8 . The technical material in these sections is clearly presented, and Brown illustrates the concepts with useful examples from language testing.

In the last chapter, Testing and curriculum, Brown clearly shows that testing must be viewed as an integral part of the larger curriculum in a 
language program. Because tests are often seen as divorced from teaching and learning, this may be the most important chapter in the book. As Brown points out, it is essential for teachers and administrators to recognize that teaching, learning, and testing all occur in the same context. Although we often study testing as though it were an isolated entity, all parts of a language program (needs analysis, goals and objectives, testing, materials development, teaching, and program evaluation) are in fact interrelated. In this final chapter, Brown presents an excellent and necessary discussion of how each component in a language program feeds into and affects all other components.

Strong points in Testing in Language Programs include end-of-chapter summaries, review questions, and application exercises. An answer key to the exercises is provided at the end of the book. One drawback to the text may be the amount of attention given to statistical details. Regular ESL classroom teachers frequently comment that testing is a highly specialized area that should be left to those with a keen interest in the topic. Instead of encouraging a greater understanding of testing, the statistical chapters may serve to intimidate readers. Using it as a course textbook, however, an instructor can choose to focus on certain topics over others depending on the background and interests of the students. Furthermore, the extensive coverage of test-related statistical issues makes Testing in Language Programs an excellent resource book.

To enhance students' understanding of the text, an instructor may want to bring in other materials. Samples of ESL students' spoken and written work can be assessed, local ESL tests can be evaluated, and students can construct test items based on the goals and objectives of various ESL programs in their locale. In terms of standardized tests, descriptive information and sample forms of tests are usually available from the test producer. In some cases testing agencies offer seminars and workshops to discuss test development. Reviews of language tests can be found in Alderson, Krahnke, and Stansfield (1987) as well as in the journal Language Testing.

In my opinion, Testing in Language Programs is a choice text for an ESL testing course. Two years ago I taught a course in ESL assessment. The textbooks available at the time were either too technical or their aim was primarily to provide ESL teachers with ideas for developing a variety of test items. Instead of using a core text, we relied on journal articles and chapters from an array of books on testing. For this reason I am pleased to see the publication of Testing in Language Programs, and I have no qualms about adopting it for future testing courses. Overall, I recommend that instructors 
seriously consider using Testing in Language Programs as a core text in their TESL programs.

\section{References}

Alderson, J.C., Krahnke, K.J. \& Stansfield, C.W. (1987). Reviews of English Language Proficiency Tests. Washington, D.C.: TESOL.

Judy Cameron

\section{The Reviewer}

Judy Cameron is an assistant professor in the Department of Educational Psychology at the University of Alberta. She has taught courses in TESL methodology, learning, ESL testing, and statistics. Her research interests include learning and motivation; she is also interested in ESL materials development.

\section{Language Assessment in Action}

\section{Geoff Brindley (Ed.)}

National Centre for English Language Teaching and Research in Australia, 1995

Much work and research are being done in the field of language testing and evaluation (Alderson et al. 1995; Lussier \& Turner, 1995), but specific questions remain: How much of this work is reaching practitioners and administrators, and how much of it is applicable to their contexts? Language Assessment in Action, edited by Geoff Brindley, is an effort to demonstrate that assessment instruments are being developed and implemented in educational contexts and that information concerning these projects can be made accessible. The book presents a collection of case studies in ESL settings in Australia. The reader is walked through various projects that give insight into the rationale, procedures, decision-making, and challenges involved in any given instrument development venture. The context of the book is specific to the situation in Australia, but the issues discussed, questions posed, and problems encountered have no geographical boundaries and are pertinent to language assessment in general.

Language Assessment in Action is organized into 11 chapters with an introduction by the editor, Geoff Brindley. The introduction summarizes the chapters, which are essentially separate articles discussing the development and implementation of assessment procedures in different places and under different conditions. He goes on to make a case for the commonality among them and thus to justify the purpose of the book, that is, to present case studies to illustrate "the way in which assessment tools have been constructed to meet the needs of particular groups" (p. 1). He feels there is a gap in the literature in this respect.

In reality, 10 case studies are presented, even though there are 11 chapters. Chapter 6 , written by the editor, gives an excellent overview of issues 
and questions in the area of competence-based assessment (this is an example of performance testing or assessment which is the more widely employed term). Due to its content and general relevance to the other chapters, however, it almost appears out of place. Putting it at the beginning might have been more effective in that it would serve as a lead in and help set the context for the reader in terms of assessment issues.

Chapters 1, 2, and 3 can be categorized together in that they address system-wide procedures that were developed for specific large-scale populations in Australia. Each chapter, however, discusses a different project and therefore stands on its own. In Chapter 1, McDowell describes the procedures involved in developing a test for overseas-qualified teachers, which included identifying the main domains of discourse that operate in a school community and determining the components of language competence that characterize an effective teacher. She demonstrates how Bachman's (1990) model of language ability was used as a starting point for test development. The detailed account of test construction is well done and can be appreciated almost as a guide, but the follow-up time devoted to reliability and validity appears to fall short in comparison. A more thorough discussion on these features would help confirm the important original rationale, which was to draw on Bachman's theoretical framework of communicative language ability, and would enhance the argument for construct validity. McKay, in Chapter 2, describes a collaborative project that resulted in an assessment and reporting package for primary and secondary learners. The process description of this project is valuable, especially for the concern it demonstrates in ensuring a correspondence between teaching, learning, and assessment. It provides a common reference for teachers of ESL students, enabling them to monitor progress on an ongoing basis. As in Chapter 1, it discusses and draws on a theoretical foundation (in this case Bachman \& Palmer, in press), but once again does not inform the reader enough about the validity issues that appear encouraging. Mincham, in Chapter 3, describes an approach to language assessment that can serve different levels in the educational context-the classroom, school, and system. It focuses on the needs of ESL learners who are mainstreamed into regular primary and secondary classrooms. Using systemic-functional linguistic theory, the needs that students have concerning the production of written and oral tasks were identified. Through teacher participation, activity-based assessment exemplars were developed to be integrated into a portfolio approach to assessment and the criteria for assessment was made explicit. Results of the project appear encouraging in that the assessment procedures have been noted as an effective tool, but no specific information is provided. The account of the process is valuable just as in Chapters 1 and 2.

Chapters 4 and 5 move the reader away from curriculum/assessment integration tasks to assessment of general language proficiency in adult ESL 
learners irrespective of any particular curriculum. They both focus on the Australian Second Language Proficiency rating scale (ASLPR) which is used in the Australian Adult Migrant English Program (AMES). Those involved in computer-based programs will find Chapter 4 of interest. Corbel discusses the development of Exrater, a computer program aimed to help language assessors who are using the ASLPR. It is based on an "expert system" and has improved reliability by guiding assessors to focus on the specific criteria set out in the rating scale. In Chapter 5 McIntyre provides an in-depth review of the ASLPR. He points out problems with rating scales and provides suggestions for enhanced rater reliability. He recognizes the need for validation studies for this widely used rating scale and suggests specific directions for content and construct validity studies.

To this point in the book the reader has been presented with case studies. As mentioned above, Chapter 6 written by the editor is a departure from this. Brindley provides an excellent overview of competence- or performancebased assessment and visits many of the themes that are found in other chapters throughout the book. In particular he stresses the importance of a clear definition of the language domains being assessed as a starting point for the development of any assessment procedure.

Chapters 7 through 11 are most informative and accessible to the reader. To begin with, they include general reviews of the literature that help situate the case studies in a broader context. They also expand on project outcomes that make reliability and validity discussions more meaningful. These are features that are generally lacking in Chapters 1 through 5 .

Clarkson and Jensen, in Chapter 7, describe the development of a taskbased instrument used to assess the achievement of course objectives. The target group is adult immigrants in an English for professional employment course. Using Bachman's (1990) model as a theoretical framework, they provide information on each step in the process. Their work is exemplified well through task components, rating scales, and certificate criteria that are all included in the appendices.

Chapters 8 and 9 are a wealth of information for anyone interested or involved in criterion-based assessment. In Chapter 8 Grierson describes a study that examined the nature and quality of classroom assessment of teachers at the secondary level involved in intensive ESL courses. Gunn, in Chapter 9, describes the development of a criterion-based assessment procedure and then follows through with a study aimed at investigating the impact of the adoption of this procedure in adult immigrant ESL classrooms.

The last two chapters in the book deal with self-assessment (SA) and the benefits it can yield for the learners themselves. Cram, in Chapter 10, provides the reader with a rationale for the use of SA procedures. She then goes on to provide a guide aimed at helping teachers to introduce SA into a language instructional setting. This section is probably the most effective in 
the book in terms of describing and illustrating a procedure. She demonstrates how SA training and involvement for both teacher and learner are paramount. Wilkes, in Chapter 11, investigates the relationship between SA, peer-assessment, and teacher-assessment. She replicates an earlier study and reports considerable variability in assessments. She attributes this in part to a lack of training for all participants and argues for greater attention to training, which is consistent with Cram's theme in Chapter 10.

Brindley appears to have succeeded in fulfilling his purpose for this book. It is in general an accessible volume to read and it does demonstrate specific examples of the development of assessment procedures to meet the needs of particular groups. Through the presentation of case studies, common issues and concerns in the area of assessment become evident. It is also interesting to note that most chapters draw on current theoretical frameworks of communicative language ability, in particular those proposed by Bachman (1990) and Bachman and Palmer (in press).

In order to make a stronger case for the purpose of this book, however, I would suggest an alternative to the present chapter sequencing. I would start with Chapter 6, a powerful review of competence assessment issues and continue with Chapters 7 to 11 . The projects in these chapters are placed in a clear theoretical framework with follow-up discussions concerning outcomes and validity issues. For these reasons, the reader can identify with the content even though it is specific to a certain location. I would place Chapters 1 through 5 at the end, not only for the topics addressed in relation to the others, but also for the reasons mentioned above. If the intent was to write in an accessible way, this should not be interpreted as leaving out theory or a discussion of its relation to outcomes. Quite the contrary, such a discussion should be included for understanding.

The process of evaluation is gaining more attention in institutions and classroom contexts. This book illustrates an effective approach by giving examples of the types of assessment projects that are actually taking place. It can appeal to different audiences, but its strength lies is providing theoretically based how-to accounts of the development of assessment procedures to meet specific needs. The content is informative and the reference lists should be noted.

Carolyn Turner

\section{References}

Alderson, J.C., Clapham, C., \& Wall, D. (1995). Language test construction and evaluation.

Cambridge: Cambridge University Press.

Bachman, L.F. (1990). Fundamental considerations in language testing. Oxford: Oxford University. Bachman, L.F., \& Palmer, A.S. (in press). Language testing in practice. Oxford University Press. 
Lussier, D., \& Turner, C. (1995). Le point sur l'évaluation en didactique des langues. Anjou, PQ:

Centre Éducatif et Culturel.

The Reviewer

Carolyn E. Turner is Associate Professor and Certificate Program director in the Department of Second Language Education at McGill University. Her main fields of research are testing and evaluation and curriculum development in second language education.

\section{LSP: Problems and Prospects}

Rosemary Khoo (Ed.)

Anthology Series 33. Singapore: SEAMEO Regional Language Centre, 233 pages, paperback. ISBN: 9971-74-047-8, 1994

\section{The Practice of LSP: Perspectives, Programmes and Projects}

Rosemary Khoo (Ed.)

Anthology Series 34. Singapore: SEAMEO Regional Language Centre, 282 pages, paperback. ISBN: 9971-74-048-6, 1994

\section{Introduction}

LSP: Problems and Prospects and The Practice of LSP: Perspectives, Programmes and Projects are numbers 33 and 34 in SEAMEO's (Southeast Asian Ministry of Education Organization) Regional English Language Centre's (RELC) Anthology Series. These anthologies include papers from RELC's 1993 Seminar on Language for Specific Purposes (LSP).

In her introductory remarks, Rosemary Khoo, editor, notes that after 25 years, LSP as a discipline is gaining new direction. The field is being transformed from a largely academic orientation to one that takes a "more pragmatic, interdisciplinary, and balanced approach that attempts to integrate LSP with context ... of text, the local context and the context of culture and global concerns" (Anthology Series 33, p. ii). Khoo provides a useful overview of each article in each book that will guide readers in papers relevant for them. A list of contributors and their institutions is provided at the end of each volume.

Anthology 33, comprising 14 papers, is theoretical, academic, and analyti$\mathrm{cal}$, posing problems and issues and sometimes suggesting solutions. The 18 papers in Anthology 34 focus on teaching and administrative practice and operations.

Authors have their own approach to LSP and individual writing styles. I found most to be succinct, well written, and appropriate for the volume in which they appear. If I were to give any overall negative criticisms to these two books it would be the large number of typographical errors (I spend much of my working life editing documents), particularly in Anthology Series 34. Also, although I gained a great deal in terms of insight into LSP as 
a subdiscipline, I discovered fewer practical or innovative applications than anticipated. This is especially true for Series 34, which is meant to be practical. For example, I found little new information in the many papers on EAP, which is the area in which I currently teach. My general impression is that the two anthologies are more theoretical than practical. Even in the second volume, at least one third of every article is theoretical. The volumes contain articles that are fairly general on LSP and a few that are for specific audiences. Often there is a strongly Asian perspective, which makes sense given the origin of the books. Those who are working in Asia or plan to work there in future will benefit from these papers.

The rest of this review provides an overview of the papers in each book with an indication of their relevance to readers.

\section{LSP: Problems and Prospects}

Papers in this Anthology Series 33 range in length from 15 to 20 pages. Authors of the papers are from Singapore, Hong Kong, Australia, the United Kingdom, and the United States of America. The book covers a wide range of topics of interest, particularly to LSP theorists and researchers. The first paper provides an overview of the state of LSP. Papers 2, 3, 4, and 5 explore genre analysis in ESP. The 6th and 7th papers deal with LSP glossaries and corpora. Papers 8 and 9 address the topic of academic writing. Papers 10 and 11 are on ESP in the workplace. Testing is the topic of papers 12 and 13, and the final paper rounds off the volume with a the state of LSP research. Following is a brief abstract of each paper based on a combination of Khoo's introduction and my reading.

Alan Waters contrasts the study of ESP in the 1970s and 1980s with the current state of ESP theory. He discusses possible solutions to the deficiencies of the past, particularly the problem of the widening gap between theory and practice in ESP. This is a substantial article that will be of interest to anyone interested in LSP. It is well placed at the beginning of this volume and sets the stage for both books.

Ann Johns discusses how genre and discourse community relate to ESP, pointing out how features and rules of genre can assist ESP teachers. It is one of the most practical documents in the book. In the next paper, Makhan Lal Tickoo effectively counters Johns' arguments on genre by challenging a genre-based approach in favor of an approach that better serves Asian learners by understanding and addressing the social and institutional context of their learning. The power of his argument lies in the fact that he is proposing a paradigm shift from the imposition of approaches from outside (i.e., from the English-speaking world) in favor of approaches developed in Asia for Asians. Unfortunately, he uses a confusing numbering system in his article that makes it difficult to follow. Vijay K. Bhatia continues the discussion on genre by supporting it as a practical and appropriate basis for a communicative curriculum. She calls for the use of authentic, discipline- 
specific texts, an interdisciplinary approach in which ESP professionals work with professionals from specialist disciplines, the need for means analysis as well as needs analysis, and the importance of accountability of courses through student evaluation. She also repeats Tickoo's call for consideration of the local ESP context. The article is readable and contributes well to the genre discussion. The final paper on genre is by Heather L. Kay who presents a model that integrates genre and process approaches to the ESP curriculum. After a long discussion on the terminology of genre, complete with what I found to be a rather confusing diagram on the topic, she discusses a "transgeneric approach" in which generic features cross several disciplines. Her article is well-written and made interesting by her practical illustrations.

The next two articles would be useful to those interested in the development of glossaries and corpora. I found Alan Davies' article on glossary to be extremely detailed in terms of both theory and practice. I was frustrated by the long discussion on the difference between glossary and encyclopedia, and by the lack of explicit relationship to LSP. Flowers' paper compares two discipline-specific corpora, concluding that corpora for lectures are different from textbook corpora in the same specialist field. This study is of particular interest to curriculum developers.

A paper by three Australian authors, Susan Kaldor, Michael Harriman, and Judith Rochecouste, begins the section on academic writing. They discuss an ongoing project that examines the interaction between grammar and discourse. Although the article is easy to read, it is quite theoretical and would be of interest only to researchers in this area. Few conclusions have yet been reached in their study that would transfer into practice. Betty Samraj continues the discussion of academic writing for professionals and students in the field of natural resources. She notes that students become "acculturated into a discourse community" (p. 127). In a multidisciplinary field such as environmental studies, students must, therefore, learn to work in several discourse communities simultaneously. Her study analyzes students' writing in a number of contexts, differing audiences, and student self concept as researchers or as students. The study is interesting and of possible value to researchers and theoreticians.

Kaye Malcolme begins the three articles on LSP in the workplace by discussing power relations in communications between native and nonnative speakers of English at work. She notes that people must learn to adapt strategically to the environment of the workplace, partly through the negotiation of power roles, which are learned through problem-solving activities in the classroom. The paper examines teachable content beyond the mechanics of language. Malcolme lists five applications to classroom practice. I found the article informative, although I wished I had had a stronger background in sociology as I read. Cynthia Lee and Terence Lo continue the theme of power in the workplace, describing a study that analyzes materials 
for vocational EFL. They conclude that certain materials maintain the status quo rather than preparing students to participate actively at work. They begin with a description of the need for appropriate workplace English, and then move to a detailed discussion of Halladay's analytical framework. The last two sections of the paper include an intriguing discussion of how language can reinforce social and personal identity at work. The author argues for the inclusion of "critical language studies" in English curricula to teach students about language and empowerment. This paper is of interest to theoreticians and practitioners who seek information on sociological issues in ESP.

Don Porter raises the concern of wasted resources in the development of specialized LSP tests. He notes that general proficiency tests can predict student success regardless of specialty, so there is no need to use scarce resources for specialized test development. The article is brief and succinct and raises the issue again of the need to subdivide ESL from EFL and from EAP. In her paper, Anne Brown notes that both professional and linguistic competencies must be tested to predict learners' capabilities, adding that this would necessitate the involvement of discipline specialists in curriculum planning. She describes a test developed for Japanese tour guides that involves industry specialists as well as language specialists. This article would be of interest to those involved in both curriculum planning for LSP and in testing.

The concluding paper by Tony Dudley-Evans finishes this volume appropriately with a review of three major themes in recent ESP research: classroom research; text-based research; and research based on insights gained from subject specialists. He describes an example for each research theme and lists other areas of research that he believes LSP researchers could pursue.

\section{The Practice of LSP: Perspectives, Programmes and Projects}

The papers in Anthology Series 34 are 10 to 25 pages in length and address a wide variety of topics. The majority of the papers, at least in part, are on English for Academic Purposes. Authors are from Thailand, Indonesia, Malaysia, Singapore, Hong Kong, Japan, Australia, New Zealand, Canada (St. Mary's University), and Spain. I again use Khoo's paper overviews combined with my reading of the papers to provide an overview of the volume's contents and relevance for readers.

David Crabbe's paper begins the book with strategies to incorporate process objectives in classroom activities and materials. He suggests a problem-solving perspective around which teachers can balance task and content. He notes that ESP teachers must go beyond needs analysis and utilize a problem-solving approach to address the variety of specialization areas that they will be called on to teach. Crabbe describes the syllabus at his institu- 
tion. The paper is useful and readable, motivating teachers to use a problemsolving approach.

Ian G. Malcolm's paper examines four types of course to illustrate that some correlate more closely to degree studies than others. Although the paper is informative and could assist administrators in EAP programs justify degree credit for certain EAP courses, it is more theoretical than practical.

Rosemary Khoo's paper informs Asian ESL professionals about a project that makes available to them at RELC in Singapore the following resources on English for business and technology (EBT): 78 EBT course descriptions; 45 company profiles; other EBT sources; directors of registered users to promote a network of practitioners; small collection of authentic materials. The paper is useful to Asian teachers in need of resources and who have the luxury of time to contact RELC to obtain what is required for their course or program.

Three papers address computer applications in LSP. Fattah Lauder's paper describes how computers can be used to keep up-to-date records of syllabi and teaching materials that respond to ever-changing needs. It offers suggestions on electronic storage of materials, favoring a hierarchical system. It also describes some commercially available software to facilitate filing and cataloguing. Lauder seems reluctant to get rid of hard (paper) copy in favor of electronic files. The paper is detailed. It is easy to read and not too technical, although sometimes repetitive. Electronic storage of syllabi, materials, and lesson plans is not necessarily a new idea and is relevant to ESL programs generally. Nevertheless, it has motivated me to examine the possibility of actually trying it in our program. Steve Auroza describes how to use a computer to analyze corpora, and how corpora can be utilized by EAP instructors. The article will be of particular interest to course developers who want to know how to analyze and construct a corpus. He notes that one of the greatest benefits of corpora construction is the bringing together of ESL professionals with subject specialists. Three authors, Lai Phooi Ching, Irene Wong and Dorothy Cheung, discuss the use of a computer application known as a Concordancer, which is capable of fast word searches displayed in context. The authors describe a case study with engineering students using this program. Students work on their own and learn to deduce rules using this program. However, not all students reported success in learning and not all favored this approach to learning. The article left me puzzled. On the surface it appeared that the authors were champions of this program. However, after discovering learner feedback, I am not convinced. Even so, the paper is of interest to those pursuing computer-based language education.

In their study Rajeswary A. Sargunan and Esther Chelliah-Tam compared a group of engineering technicians with a group of engineering students to determine if the same methodology can be used for groups with different goals if the discipline is similar. The paper is useful to administrators of small programs faced with placing students with different goals in the same class. 
Wanpen Tubtimtong's research focuses on three factors: linguistic aspects, pedagogical decisions, and administrative concerns in an EAP program. Of central concern is the inclusion of communicative needs expressed by learners. I found little new information in the paper. Still, it would provide an orientation to new EAP instructors.

P.W.J. Nababan outlines an approach to ESP in a secretarial college. The author focuses particularly on the importance of adjusting LSP course formats and methods to learners' differing social, educational, and cultural contexts. Again, I did not find much new here. However, Asian practitioners might gain from this description of an Indonesian program.

An interesting description of Japanese students' motives for studying English to pass exams rather than for practical purposes begins Mamoru Morizumi's paper. The author discusses the differences between ESP and EGP (English for general purposes), why ESP is not popular, and the difficulties of teaching ESP in Japan. He notes that there is a continuum between ESP and EGP and that each can gain from the teaching/learning lessons of the other. He suggests practical ways that ESP can be made more attractive in Japan. The paper is of particular relevance to professionals in Japan, as well as to those who are interested in similarities and differences between ESP and EGP and what one approach can contribute to the other.

Readers familiar with the book Campus Bound, produced by EAP professionals at St. Mary's University, will be interested in reading Jane Jackson Fahmy's paper that describes a research project and subsequent development of a similar course in Oman. Fahmy's course is designed to develop students' skills in note taking and critical thinking. A sample theme unit is included in the appendix. She also points out 10 implications of her study that provide a useful review for EAP instructors.

Lynette Bowyer proposes an individualized approach to EAP to develop autonomous learners. The article opens with a poignant quotation from a learner: "The most important point from studying at universities is that I must learn by myself" (p. 177). Bowyer describes this as a tremendous leap for most students entering universities in the English-speaking world. She lists six areas that need to be included in the EAP syllabus: ways to build student independence; materials that prepare students for academic study in their specialty; needs analysis (of students and academic courses); making learning strategies explicit; and more professional development for EAP instructors. I found parts of the paper confusing, parts new and helpful, and parts old. Still, program developers would gain from a careful reading of this entry.

M. Wales discusses the state of EWP in Australia and why general English must be incorporated into EWP programs in that country to meet the needs of both learners and managers. Wales favors Widdowson's approach to language instruction that builds on learners' interpretive skills. Wales em- 
phasizes a need to use the workplace as a way to orient learners to the workplace culture. The article is of particular interest to professionals in EWP and to those who are interested in ways to combine ESP and EGP. Note, Khoo has omitted an overview to this paper in her foreword.

David Hall's paper is related to the previous one in that it also addresses general English, particularly communicative competence. Hall describes Talkbase, an eight-week program that addresses communicative competence in a class of learners with differing specializations. Rather than bemoaning the heterogeneity of the learners, Hall notes how differences can enhance learning experiences. He describes the immersion approach to build learner autonomy through encouraging problem-solving throughout the program. The article is instructive and well written and will be of particular interest to those who take student-generated curricula and learning seriously.

The problems of teaching shift workers in a cross-cultural work setting is addressed in Philip Bebb's paper. Bebb discusses strategies to overcome workplace responsibilities, which include: program goals of a flexible curriculum to meet specified targets (e.g., modularization); frequent small-scale assessments and evaluations; and opportunities for ongoing improvement through short courses for learners in this kind of situation. He points out ways to promote learning outside of the classroom through self-study materials, lessons on site, social functions, and self-access centers. He also describes cross-cultural workshops to help employees work together. This is a useful paper with new, practical, and realistic ideas for those who find themselves developing ESP programs in a cross-cultural setting.

Alex Teasdale outlines a project that aims to develop a standard English test for new air traffic controllers (ATC). The paper details the development of the test, particularly the development of interactive portions. Seven considerations are discussed thoroughly. The paper is rather difficult to read because of its use of technical terminology of ATC and of evaluation. It is written for a specialized ATC audience. However, test developers may gain from reading it.

Quality assurance is the subject of Christine Tan's paper. She describes how ESP programs can benefit from the standards set out in Singapore's ISO 9000 (International Organization for Standardization), which is a standard for business and industry. She outlines the ISO 9000 definition of quality and the 20 elements of quality assurance that can be applied to ESP. She notes that quality assurance documents what is done, rather than what should be done in a program, pointing out that by objectively observing ourselves, we can improve our programs. Because quality assurance and accountability currently seem to be primary in most of our minds, the paper is worth a read, particularly for program administrators.

The book ends with the volume's longest paper, written by three authors: Tien M. Soedradjat, R. Soegando, Tofan Hardjanto, and Hywel Coleman. It 
discusses an academic link among institutions in Indonesia and the United Kingdom. The cooperation among these institutions is intended to promote cross-cultural understanding and sharing of professional concerns. The paper provides the background to and administration and organization of the link, as well as its expected and unexpected outcomes. It concludes with an evaluation of the project and discusses the benefits of cooperation among institutions. The paper proposes an innovative idea that will be enhanced in future by communications technology. It is an excellent choice as a final paper.

Ruth Epstein

The Reviewer

Ruth Epstein, is an ESL Specialist/Instructional Designer in the Extension Division, University of Saskatchewan. She has consulted as a curriculum specialist in many international settings.

\section{The Pulse of the World: Refugees in our Schools}

\section{Isabel Kaprielian-Churchill and Stacy Churchill OISE Press}

The Pulse of the World is about refugee children in Canadian schools. The topic itself is set in international, national, provincial, local, and a whole host of professional jurisdictions, all of which have tended to generate disparately produced source documents about refugees, scattering papers to the wind. This volume, alternatively, brings together historical, social policy, and educational perspectives and endeavors to address the circumstances of real people in Canadian schools and communities.

The contents include a report of life in a refugee camp on the CambodianThai border, done in 1987; a look at historical and policy dimensions of the Canadian refugee program and their implications for children; a chapter on the characteristics of refugees; a look at factors affecting school performance; and a section detailing conclusions reached by the study and its recommendations.

This is an attractive book accessible to all kinds of readers. It is illustrated throughout with photographs, news clippings, and statistical charts about refugees. Given the extremely large numbers of refugees recently settled, particularly in southern Ontario, it is also timely. As the authors identify, Canada continues to depend on immigration as a strategy for population development. Schools need to build this awareness into their planning and programming.

The authors present an extremely thoughtful case, particularly for improving the treatment of refugee youth and young adults in the regular school system. Factors affecting school participation and performance are described. The problem of appropriate secondary education is an example. 
Age on arrival, lack of educational preparation, and lack of responsive resources can all affect whether a refugee youth will stay in school or become a dropout. These same factors, though, apply to many marginalized Canadian-born youths affected by migration, abuse, and neglect. Connections need to be made between the experience of refugees and those of other at-risk students. Unfortunately, in this book such connections are not made. Refugees are treated as special and separate.

The distinction between refugees and immigrants is also an issue in this book. Although experiences do differ, the authors sometimes present more general immigrant issues without acknowledging their broader import. Family experience of schooling is an example. The school is presented as a "source of great frustration" for refugee families whose cultural experience of schooling has been conservative. Yet a great many immigrant families face the same issues of religious accommodation and unfamiliarity with the educational system. The specific and important problems of refugee familiesrelating to posttraumatic experience and dislocation-become lost in a general discussion of culture, language, and schooling.

More noticeably absent in this book, however, are connections-opportunities for Canadians to consider their own history as a country built largely by refugees and to appreciate the contributions that continue to be made by more recently arrived refugees to this country. Although the United Empire Loyalists are cited as an early refugee movement, missing is any reference to the vast numbers of Scots, Irish, Ukrainians, and others who came because there were no alternatives. Many of these people too had been put off the land and forced into exile. The descendants of these early refugees today are looking for connections in a Canadian context in their search for identity. Yes, these new people are like us. They are us. We need to say it.

The Pulse of the World will be a useful resource for educators, students, social workers, and mainstream professionals interested in and attuned to the needs of refugees in Canadian schools.

Laura Ho

\section{The Reviewer}

Laura Ho is president of the Community Cultures Institute and works as a researcher and consultant with language, education, and culture. She completed her doctorate in education at the University of Alberta. Laura is a descendant of Scots emigrés. 


\title{
Exploring Gender: Questions and Implications for English Language Education
}

\author{
Jane Sunderland ( $E d$.)
}

New York: Prentice Hall, 1994

This edited book contains 21 short essays, divided into four sections ("quadrants"), with a general introduction and introductions and conclusions to each section. The editor intends "to help trainee and practicing language teachers, including experienced language teachers, look at their work through gendered eyes" (p. 8). Indeed, as becomes clear by the end of the book, the editor believes that all teachers (and students) inescapably come to classrooms with gendered eyes, gendered bodies, and minds altogether, and her aim here is to encourage critical examination of what that gendering might mean for students, teachers, and the wider society.

The first quadrant of the book is concerned with examining generally the resources offered by English for expressing gender and how speakers of English use those resources. Matters of vocabulary (generic he-man, for example) are discussed, as are strategies designed to neutralize or confront the sexism implicitly or explicitly customary in statements of English usage. Two articles in this section investigate the hypothesis that men and women use the resources of English differently, with one describing complimenting behavior of American and New Zealand men and women, and the other describing how American university student men and women responded to problem descriptions. Illustrating that no simple dichotomies between male and female linguistic behavior will be adequate to account for the data, one author (Shân Wareing) argues that "feminist researchers cannot afford to ... ignore the relationship between conversational interaction and patriarchal power-how conversation both manifests and helps maintain patriarchy" (p. 38).

The second quadrant of the book examines materials used in English as a foreign language teaching. The focus of interest here is how textbooks, pedagogical grammars, and learners' dictionaries might contribute to stereotyping and domination of women. The first article in this section is by Robert O'Neill, author of a 1970 text that was used as an illustrative example in a 1976 article critical of the way women were treated in textbooks (Rees-Parnell,1976). Here O'Neill defends his use of "stereotyped" characters and considers what kinds of standards might be appropriately applied to the presentation of characters and situations in textbooks. Another article in this quadrant by David Carroll and Johanna Kowitz illustrates the use of computer concordancing to study the presentation of women and men in recent ESL and EFL textbooks, showing that even when attempts are made at fairness, "the image of women portrayed [in the widely used textbook series 
they examined] is overwhelmingly of passivity, physical characteristics, menial roles, irrational worries, constant undemanding activities, and not of economic activities (hence textbook women are not rich or poor)" (p. 82). Two essays examine initiatives designed to address sexism in ELT materials: the first provides "Guidelines for the Representation of Women and Men in Foreign Language Teaching Materials," and the second is the transcript of an interview with Bessie Dendrinos, head author of a textbook series that "systematically question[s] sexist stereotypes as well as the social world it constructs for learners" (p. 121). The final contribution in this quadrant is entitled "An International EFL Publisher's perspective" in which its author, David Haines, reminds readers that publishers are constrained by market demands and that if their potential customers are uninterested in or hostile to Western European notions of sex equity, publishers probably will not publish books of this sort.

The third quadrant entitled "Classroom Processes" examines what happens in classrooms as female and male students work with one another and with female and male teachers. Research concerned with establishing whether there are differences in the experiences of males and females in classrooms has been considerable in educational research generally, and three of the articles in this section take those concerns to EFL classrooms. Another describes how concerns about gender might be incorporated into teacher training courses; the final article describes a "writing their lives" project for women who are mothers of Amerasian children in an Asian refugee center.

The final quadrant, "Beyond the English Language Classroom," is concerned primarily with the economic, political, and social realities of English language teachers. Citing Pennycook's (1989) observation of the "gendered division of the work force, a hierarchically organized division between male conceptualizers and female practitioners" $(1989$, p. 610), readers of this section are encouraged to consider how female teachers might involve themselves more centrally in the political decisions affecting their workplaces. One teacher's diary of her working life throughout a pregnancy and after the birth of her second child points out issues of how women manage their demanding responsibilities and what sorts of support might be offered to women. Finally, a description of the British group Women in TEFL and their work is included.

The publication of this book is certainly to be welcomed. It is the first, to my knowledge, textbook-length examination of gender and foreign language teaching and in addition to its many other strengths, it provides lengthy and comprehensive reference lists of scattered presentations, articles, and manuscripts valuable for those interested in following up.

An examination of gender in language teaching requires consideration of material in a number of different fields: sociology, education, feminist 
scholarship, discourse analysis, applied linguistics, and so on, and the references provided here will help others.

I understand the editor's decision to include short essays on a range of topics, given that we have as yet no (or few) other textbooks that cover the same ground. However, it is possible that the brevity of the essays is at least partly responsible for the fact that none of the writing in this book seems particularly strong or impassioned. Although we are presented with the story of a woman refugee, mother of a stigmatized Amerasian child, or the diary of an overworked, overtired, and overwhelmed teacher and mother, the shortness of the contributions, I think, contributes to the result that little pain is communicated. In discussing issues of fundamental social justice, the even-handed coolness of tone of the collection sounds a little peculiar to my ears. The possibility exists, of course, that my difficulty with a comment like the editor's "It would be a pity if EFL textbooks were actively to contribute to women and girls developing more negative self-concepts than do men and boys" (my italics, p. 59) is merely reflective of cultural differences in discourse. However, in such a context, the publisher's reminder in the second quadrant that "the international market" probably isn't quite ready for sexual equality, and so books promoting it aren't published, or O'Neill's argument that restricting textbooks to "this or that political, religious or social ideal" makes them less interesting (p.71) do not strike us as offensively as they might. In my work with teachers and prospective teachers, I like to have them read passionately as well as elegantly argued pieces on the domination of women and other powerless members of our society and to have them consider the effects of practices of domination on both the oppressed and the oppressors. Although perhaps appropriate for another sort of audience, this book would not meet my needs in this regard.

The editor has attempted cohesion between the diverse articles and sections with meticulous cross-referencing and the introductions and conclusions to each quadrant. Better than many other edited collections, this book demonstrates connections. In one important issue, however, contradictory "lines" are presented without comment, which would be a problem for me in classroom use. Several of the authors of the essays refer without critical comment to studies that demonstrate differences (actually, dichotomies) in behaviors, talents (language learning aptitude), learning styles, and strategies between women and men. Tannen's (1991) argument that gender differences reflect different cultural milieux for women and men is cited several times. The variety of feminist critiques of positing either innate or culturally derived dichotomies between women and men are referred to in passing by both Shân Wareing and the editor, but little is made of these critiques. Shân Wareing argues that the asymmetry in power relations between women and men must be part of our analysis, but again, possibly because of the brevity of the contribution, this argument is not developed 
fully. I personally wish this line were better explicated and illustrated in this book, interested as I am in seeing gender as a "system of culturally constructed relations of power, produced and reproduced in interaction between and among men and women" (Susan Gal, 1991, p. 176).

In the general introduction the editor states that "Exploring Gender: Questions and Implications for English Language Education has a teacher education rather than training function" (p. 8) in the sense that it is intended not to give teaching tips or strategies, but to engage practitioners in an investigation of these matters in their work. I believe the book accomplishes this aim. Participants in undergraduate as well as graduate courses in TESL methodology might be directed toward this book for its breadth of consideration of the issues. I would use a great deal of supplementary material with it to accomplish the aims I would have in such an endeavor.

Kelleen Toohey

\section{References}

Gal, S. (1991). Between speech and silence: The problematics of research on language and gender. In M. di Leonardo (Ed.), Gender at the crossroads of knowledge: Feminist anthropology in the postmodern era. Berkeley, CA: University of California Press.

Pennycook, A. (1989). The concept of method, interested knowledge, and the politics of language teaching. TESOL Quarterly 23 (4), 589-618.

Rees-Parnell, H. (1976). Women in the world of Kernal Lessons Intermediate. ARELS Journal 2 (2), 39-31.

\section{The Reviewer}

Kelleen Toohey teaches in the Faculty of Education at Simon Fraser University. She is interested in minority education and has worked with teachers of ESL, heritage and First Nations languages. 